DOI: $10.17516 / 1997-1397-2021-14-1-57-68$

УДК 536.25

\title{
Construction of Exact Solution Describing Three-layer Flows with Evaporation in a Horizontal Channel
}

\author{
Ekaterina V. Rezanova* \\ Altai State University \\ Barnaul, Russian Federation
}

Received 26.08.2020, received in revised form 07.09.2020, accepted 26.10.2020

\begin{abstract}
The paper considers the flow in a three-layer system "liquid-liquid-gas" in a horizontal channel with solid impermeable walls. The evaporation process at the thermocapillary interface of the liquid and gas is taken into account. The Soret and Dufour effects are taken into account in the upper layer filled with a gas-vapor mixture. The system of Navier-Stokes equations in the Boussinesq approximation is used as a mathematical model. A temperature regime is set on the channel walls. Liquid evaporation is modeled using the conditions at the liquid-gas interface. Exact solution of a special type describing the flow in a three-layer system is constructed. The velocity profiles are presented on the example of the "silicone oil-water-air" system for various values of gas flow rate, longitudinal temperature gradients at the system boundaries, thicknesses of liquid and gas-vapor layers.
\end{abstract}

Keywords: three-layer system, exact solutions, evaporation, Soret effect, Dufour effect.

Citation: E.V.Rezanova, Construction of Exact Solution Describing Three-layer Flows with Evaporation in a Horizontal Channel, J. Sib. Fed. Univ. Math. Phys., 2021, 14(1), 57-68.

DOI: 10.17516/1997-1397-2021-14-1-57-68.

\section{Introduction}

The problem of studying convective flows has a fairly long history. But the development of high-tech technologies is constantly expanding the range of problems associated with mathematical modeling of convection and requiring a more complete and accurate description of the phenomena of heat and mass transfer [1]. A special place among such problems is occupied by the investigation of flows in the presence of evaporation or condensation. Convective flows of liquids and co-current gas flows under conditions of mass transfer at the interface are considered experimentally and theoretically $[2-5]$. The problems solved within the framework of the classical formulations of problems for the Navier-Stokes equations of a viscous incompressible liquid and its Oberbeck-Boussinesq approximations are of particular interest [6,7]. The study of exact solutions of a special type is relevant for the description of multilayer flows in connection with the possibility of investigation the influence of various physical factors on the nature of flows [8-10].

In the paper the three-layer flows of the "liquid-liquid-gas" type accompanied by evaporation at the liquid-gas interface are considered. The research is based on exact solutions of the Ostroumov-Birikh type $[11,12]$. Mathematical modeling is carried out using the Navier-Stokes equations in the Oberbeck-Boussinesq approximation. The process of vapor diffusion in the upper layer is considered taking into account the effects of thermal diffusion and diffusion thermal conductivity.

\footnotetext{
*katerezanova@mail.ru https://orcid.org/0000-0001-5287-8905

(C) Siberian Federal University. All rights reserved
} 


\section{Problem statement and construction of the exact solutions}

The flow in a three-layer system "liquid-liquid-gas" in a horizontal channel is studied. Fig. 1 shows a system of three infinite horizontal layers with solid upper and lower boundaries and thermocapillary interfaces. The lower and middle layers are filled with viscous incompressible one-component liquids, the upper one is filled with a two-component mixture of gas and vapor of the liquid of the middle layer. The coordinate system is chosen in such a way that the gravity vector is directed opposite to the $O y$ axis.

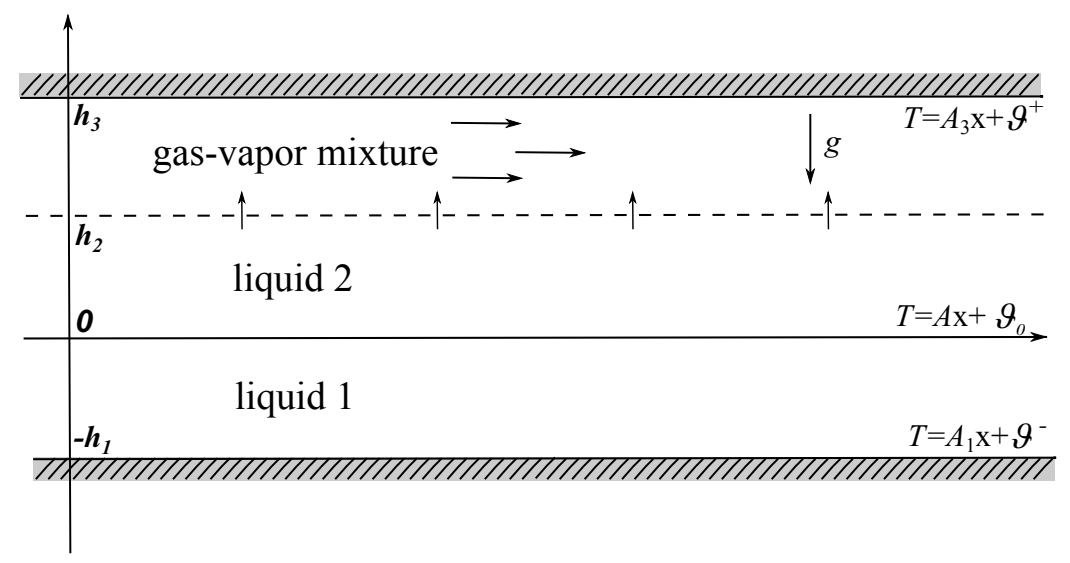

Fig. 1. Geometry of the flow domain

The system of equations for finding the velocity, temperature and pressure in each of the layers of the system, as well as the vapor concentration in the upper layer in the stationary case, is written as follows [6]:

$$
\begin{gathered}
u \frac{\partial u}{\partial x}+v \frac{\partial u}{\partial y}=-\frac{1}{\rho} \frac{\partial p^{\prime}}{\partial x}+\nu\left(\frac{\partial^{2} u}{\partial x^{2}}+\frac{\partial^{2} u}{\partial y^{2}}\right) \\
u \frac{\partial v}{\partial x}+v \frac{\partial v}{\partial y}=-\frac{1}{\rho} \frac{\partial p^{\prime}}{\partial y}+\nu\left(\frac{\partial^{2} v}{\partial x^{2}}+\frac{\partial^{2} v}{\partial y^{2}}\right)+g(\beta T+\underline{\gamma C}) \\
\frac{\partial u}{\partial x}+\frac{\partial v}{\partial y}=0 \\
u \frac{\partial T}{\partial x}+v \frac{\partial T}{\partial y}=\chi\left(\frac{\partial^{2} T}{\partial x^{2}}+\frac{\partial^{2} T}{\partial y^{2}}+\delta\left(\frac{\partial^{2} C}{\partial x^{2}}+\frac{\partial^{2} C}{\partial y^{2}}\right)\right) \\
u \frac{\partial C}{\partial x}+v \frac{\partial C}{\partial y}=D\left(\frac{\partial^{2} C}{\partial x^{2}}+\frac{\partial^{2} C}{\partial y^{2}}+\alpha\left(\frac{\partial^{2} T}{\partial x^{2}}+\frac{\partial^{2} T}{\partial y^{2}}\right)\right)
\end{gathered}
$$

Here $u, v$ are the projections of the velocity vector on the $O x$ and $O y$ axes, respectively, $p^{\prime}$ is the modified pressure (deviation from hydrostatic pressure, $p^{\prime}=p-\rho \mathbf{g} \cdot \mathbf{x}, p$ is the pressure), $\mathbf{g}$ is the gravity vector $(\mathbf{g}=(0,-g)), T$ is the temperature, $C$ is the vapor concentration, $\rho$ is the density, $\nu, \chi, D$ are the coefficients of kinematic viscosity, thermal diffusivity and vapor diffusion in the gas, respectively. $\alpha$ and $\delta$ characterize the Soret and Dufour effects, $\beta$ and $\gamma$ are the thermal and concentration expansion coefficients, respectively. Note that the diffusion equation and underlined terms are taken into account only when modeling of the upper gas-vapor layer. 
It is assumed that the solution to the system has the form $[11,12]$ :

$$
u_{i}=u_{i}(y), \quad v_{i}=0, T_{i}=\left(a_{1}^{i}+a_{2}^{i} y\right) x+\vartheta_{i}(y), C=\left(b_{1}+b_{2} y\right) x+\phi(y),
$$

where $a_{j}^{i}$ and $b_{j}$ are some constants. The index $i=1,2,3$ is responsible for belonging to the layer: the quantities with subscript $i=1$ belong to the media of the lower layer, $i=2-$ to the media of the middle layer, and $i=3-$ to the media of the upper layer. This type of solution means that only the longitudinal velocity components are non zero, whereas the transverse ones are equal to zero.

The functions of longitudinal velocity, temperature, and pressure taking into account the type of exact solutions (2) for liquids filling the lower and middle layers have the form

$$
\begin{gathered}
u_{i}=\frac{g \beta_{i}}{\nu_{i}}\left(\frac{y^{4}}{24} a_{2}^{i}+\frac{y^{3}}{6} a_{1}^{i}\right)+\frac{y^{2}}{2} c_{1}^{i}+y c_{2}^{i}+c_{3}^{i} . \\
T_{i}=\left(a_{1}^{i}+a_{2}^{i} y\right) x+\frac{y^{7}}{1008} \frac{g \beta_{i}\left(a_{2}^{i}\right)^{2}}{\nu_{i} \chi_{i}}+\frac{y^{6}}{720}\left\{\frac{g \beta_{i} a_{1}^{i} a_{2}^{i}}{\nu_{i} \chi_{i}}+4 \frac{g \beta_{i} a_{1}^{i} a_{2}^{i}}{\nu_{i} \chi_{i}}\right\}+ \\
+\frac{y^{5}}{120}\left\{\frac{g \beta_{i}\left(a_{1}^{i}\right)^{2}}{\nu_{i} \chi_{i}}+3 \frac{c_{1}^{i} a_{2}^{i}}{\chi_{i}}\right\}+\frac{y^{4}}{24}\left\{\frac{c_{1}^{i} a_{1}^{i}}{\chi_{i}}+2 \frac{c_{2}^{i} a_{2}^{i}}{\chi_{i}}\right\}+\frac{y^{3}}{6}\left\{\frac{c_{2}^{i} a_{1}^{i}}{\chi_{i}}+\frac{c_{3}^{i} a_{2}^{i}}{\chi_{i}}\right\}+\frac{y^{2}}{2} \frac{c_{3}^{i} a_{1}^{i}}{\chi_{i}}+y c_{4}^{i}+c_{5}^{i} . \\
p_{i}^{\prime}=\rho_{i} \nu_{i}\left(\frac{y^{2}}{2} \frac{g \beta_{i} a_{2}^{i}}{\nu_{i}}+\frac{g \beta_{i} a_{1}^{i}}{\nu_{i}} y+c_{1}^{i}\right) x+ \\
+\frac{y^{8}}{8} k_{7}^{i}+\frac{y^{7}}{7} k_{6}^{i}+\frac{y^{6}}{6} k_{5}^{i}+\frac{y^{5}}{5} k_{4}^{i}+\frac{y^{4}}{4} k_{3}^{i}+\frac{y^{3}}{3} k_{2}^{i}+\frac{y^{2}}{2} k_{1}^{i}+y k_{0}^{i}+\widetilde{c}_{3}^{i},
\end{gathered}
$$

where the coefficients $k_{j}^{i}(i=1,2, j=0,7)$ do not depend on $y$ and are defined as follows:

$$
\begin{gathered}
k_{7}^{i}=\frac{1}{1008} \frac{\left(g \beta_{i} a_{2}^{i}\right)^{2} \rho_{i}}{\nu_{i} \chi_{i}}, \quad k_{6}^{i}=\frac{1}{144} \frac{\left(g \beta_{i}\right)^{2} \rho_{i} a_{1}^{i} a_{2}^{i}}{\nu_{i} \chi_{i}}, \\
k_{5}^{i}=\frac{1}{120} \frac{g \rho_{i} \beta_{i}}{\chi_{i}}\left(\frac{g \beta_{i}\left(a_{1}^{i}\right)^{2}}{\nu_{i}}+3 c_{1}^{i} a_{2}^{i}\right), \quad k_{4}^{i}=\frac{1}{24} \frac{g \rho_{i} \beta_{i}}{\chi_{i}}\left(c_{1}^{i} a_{1}^{i}+2 c_{2}^{i} a_{2}^{i}\right), \\
k_{3}^{i}=\frac{1}{6} \frac{g \rho_{i} \beta_{i}}{\chi_{i}}\left(c_{2}^{i} a_{1}^{i}+c_{3}^{i} a_{2}^{i}\right), \quad k_{2}^{i}=\frac{1}{2} \frac{g \rho_{i} \beta_{i}}{\chi_{i}} c_{3}^{i} a_{1}^{i}, \quad k_{1}^{i}=g \rho_{i} \beta_{i} c_{4}^{i}, \quad k_{0}^{i}=g \rho_{i} \beta_{i} c_{5}^{i} .
\end{gathered}
$$

Here $i=1,2, p_{i}^{\prime}=p+\rho g y$ is the modified pressure.

For the upper layer containing gas, vapor is a passive addition. The exact solution describing the velocity, the temperature distribution, the vapor concentration and the pressure are written in the following form:

$$
\begin{gathered}
u_{3}=\frac{g}{\nu_{3}}\left[\frac{y^{4}}{24}\left(\beta_{3} a_{2}^{3}+\gamma b_{2}\right)+\frac{y^{3}}{6}\left(\beta_{3} a_{1}^{3}+\gamma b_{1}\right)\right]+\frac{y^{2}}{2} c_{1}^{3}+y c_{2}^{3}+c_{3}^{3} . \\
T_{3}=\left(a_{1}^{3}+a_{2}^{3} y\right) x+\frac{y^{7}}{1008} B_{2} \frac{g}{\nu_{3}}\left(\beta_{3} a_{2}^{3}+\gamma b_{2}\right)+ \\
+\frac{y^{6}}{720}\left[B_{1} \frac{g}{\nu_{3}}\left(\beta_{3} a_{2}^{3}+\gamma b_{2}\right)+4 B_{2} \frac{g}{\nu_{3}}\left(\beta_{3} a_{1}^{3}+\gamma b_{1}\right)\right]+\frac{y^{5}}{120}\left[B_{1} \frac{g}{\nu_{3}}\left(\beta_{3} a_{1}^{3}+\gamma b_{1}\right)+3 B_{2} c_{1}^{3}\right]+ \\
+\frac{y^{4}}{24}\left[B_{1} c_{1}^{3}+2 B_{2} c_{2}^{3}\right]+\frac{y^{3}}{6}\left[B_{1} c_{2}^{3}+B_{2} c_{3}^{3}\right]+\frac{y^{2}}{2} B_{1} c_{3}^{3}+y c_{4}^{3}+c_{5}^{3} .
\end{gathered}
$$




$$
\begin{gathered}
C=\left(b_{1}+b_{2} y\right) x+\frac{y^{7}}{1008} \frac{g}{\nu_{3}}\left(\beta_{3} a_{2}^{3}+\gamma b_{2}\right)\left(\frac{b_{2}}{D}-\alpha B_{2}\right)+\frac{y^{6}}{720} \frac{g}{\nu_{3}}\left[\left(\beta_{3} a_{2}^{3}+\gamma b_{2}\right)\left(\frac{b_{1}}{D}-\alpha B_{1}\right)+\right. \\
\left.+4\left(\beta_{3} a_{1}^{3}+\gamma b_{1}\right)\left(\frac{b_{2}}{D}-\alpha B_{2}\right)\right]+\frac{y^{5}}{120}\left[\frac{g}{\nu_{3}}\left(\beta_{3} a_{1}^{3}+\gamma b_{1}\right)\left(\frac{b_{1}}{D}-\alpha B_{1}\right)+3\left(\frac{b_{2}}{D}-\alpha B_{2}\right) c_{1}^{3}\right]+ \\
+\frac{y^{4}}{24}\left[\left(\frac{b_{1}}{D}-\alpha B_{1}\right) c_{1}^{3}+2\left(\frac{b_{2}}{D}-\alpha B_{2}\right) c_{2}^{3}\right]+ \\
+\frac{y^{3}}{6}\left[\left(\frac{b_{1}}{D}-\alpha B_{1}\right) c_{2}^{3}+\left(\frac{b_{2}}{D}-\alpha B_{2}\right) c_{3}^{3}\right]+\frac{y^{2}}{2}\left(\frac{b_{1}}{D}-\alpha B_{1}\right) c_{3}^{3}+y c_{6}+c_{7} . \\
p_{3}^{\prime}=\rho_{3} \nu_{3}\left(\frac{y^{2}}{2} \frac{g}{\nu_{3}}\left(\beta_{3} a_{2}^{3}+\gamma b_{2}\right)+y \frac{g}{\nu_{3}}\left(\beta_{3} a_{1}^{3}+\gamma b_{1}\right)+c_{1}^{3}\right) x+ \\
+\frac{y^{8}}{8} k_{7}^{3}+\frac{y^{7}}{7} k_{6}^{3}+\frac{y^{6}}{6} k_{5}^{3}+\frac{y^{5}}{5} k_{4}^{3}+\frac{y^{4}}{4} k_{3}^{3}+\frac{y^{3}}{3} k_{2}^{3}+\frac{y^{2}}{2} k_{1}^{3}+y k_{0}^{3}+\widetilde{c}_{4}^{3},
\end{gathered}
$$

where the coefficients $k_{7}^{3}-k_{0}^{3}$ are given by the relations

$$
\begin{gathered}
k_{7}^{3}=\frac{\rho_{3} g}{1008} \frac{g}{\nu_{3}}\left[\beta_{3} B_{2}+\gamma\left(\frac{b_{2}}{D}-\alpha B_{2}\right)\right]\left(\beta_{3} a_{2}^{3}+\gamma b_{2}\right), \\
k_{6}^{3}=\frac{\rho_{3} g}{720} \frac{g}{\nu_{3}}\left\{\left[\beta_{3} B_{1}+\gamma\left(\frac{b_{1}}{D}-\alpha B_{1}\right)\right]\left(\beta_{3} a_{2}^{3}+\gamma b_{2}\right)+4\left[\beta_{3} B_{2}+\gamma\left(\frac{b_{2}}{D}-\alpha B_{2}\right)\right]\left(\beta_{3} a_{1}^{3}+\gamma b_{1}\right)\right\}, \\
k_{5}^{3}=\frac{\rho_{3} g}{120}\left\{\frac{g}{\nu_{3}}\left[\beta_{3} B_{1}+\gamma\left(\frac{b_{1}}{D}-\alpha B_{1}\right)\right]\left(\beta_{3} a_{1}^{3}+\gamma b_{1}\right)+3\left[\beta_{3} B_{2}+\gamma\left(\frac{b_{2}}{D}-\alpha B_{2}\right)\right] c_{1}^{3}\right\}, \\
k_{4}^{3}=\frac{\rho_{3} g}{24}\left\{\left[\beta_{3} B_{1}+\gamma\left(\frac{b_{1}}{D}-\alpha B_{1}\right)\right] c_{1}^{3}+2\left[\beta_{3} B_{2}+\gamma\left(\frac{b_{2}}{D}-\alpha B_{2}\right)\right] c_{2}^{3}\right\}, \\
k_{3}^{3}=\frac{\rho_{3} g}{6}\left\{\left[\beta_{3} B_{1}+\gamma\left(\frac{b_{1}}{D}-\alpha B_{1}\right)\right] c_{2}^{3}+\left[\beta_{3} B_{2}+\gamma\left(\frac{b_{2}}{D}-\alpha B_{2}\right)\right] c_{3}^{3}\right\}, \\
k_{2}^{3}=\frac{\rho_{3} g}{2}\left\{\beta_{3} B_{1}+\gamma\left(\frac{b_{1}}{D}-\alpha B_{1}\right)\right\} c_{3}^{3}, \quad k_{1}^{3}=\rho_{3} g\left(\beta_{3} c_{4}^{3}+\gamma c_{6}\right), \quad k_{0}^{3}=\rho_{3} g\left(\beta_{3} c_{5}^{3}+\gamma c_{7}\right) .
\end{gathered}
$$

Here $B_{1}$ and $B_{2}$ have the form

$$
B_{1}=\frac{D a_{1}^{3}-\chi_{3} \delta b_{1}}{D \chi_{3}(1-\alpha \delta)}, \quad B_{2}=\frac{D a_{2}^{3}-\chi_{3} \delta b_{2}}{D \chi_{3}(1-\alpha \delta)} .
$$

All unknown integration constants that arise during the construction of exact solutions to the desired functions are determined based on the boundary conditions at the solid channel boundaries and interfaces.

\section{Formulation of boundary conditions of the problem}

Let us formulate the boundary conditions that the solutions of the system (1) satisfy.

On the lower and upper solid walls of the channel the no-slip conditions (equality to zero of the longitudinal velocities) are written in the form

$$
u_{1}\left(-h_{1}\right)=0, u_{3}\left(h_{3}\right)=0 .
$$

A linear distribution with respect to the horizontal coordinate is specified for the temperature at the upper and lower boundaries:

$$
\begin{gathered}
\left.T_{1}\right|_{y=-h_{1}}=\left(a_{1}^{1}+a_{2}^{1}\left(-h_{1}\right)\right) x+\left.\vartheta_{1}\right|_{y=-h_{1}}=A_{1} x+\vartheta^{-}, \\
\left.T_{3}\right|_{y=h_{3}}=\left(a_{1}^{3}+a_{2}^{3} h_{3}\right) x+\left.\vartheta_{3}\right|_{y=h_{3}}=A_{3} x+\vartheta^{+} .
\end{gathered}
$$


The coefficients $\vartheta^{-}$and $\vartheta^{+}$are set based on the physical parameters of the process. The longitudinal temperature gradients on the channel walls have the form $A_{1}=a_{1}^{1}-a_{2}^{1} h_{1}, A_{3}=a_{1}^{3}+a_{2}^{3} h_{3}$.

In addition to the above conditions, on the upper wall of the channel, the condition for the vapor concentration is satisfied. In this case, we assume that the vapor concentration at the upper boundary is equal to zero [10] (the condition of complete vapor absorption):

$$
\left.C\right|_{y=h_{3}}=0 .
$$

Let us formulate the conditions at the interface $y=0$ between two liquids. Continuity conditions for the tangential velocities and temperatures are satisfied:

$$
\begin{gathered}
u_{1}(0)=u_{2}(0), \\
\left.T_{1}\right|_{y=0}=\left.T_{2}\right|_{y=0} .
\end{gathered}
$$

The heat transfer condition at boundary $y=0$ takes the following form:

$$
\left.\kappa_{1} \frac{\partial T_{1}}{\partial y}\right|_{y=0}=\left.\kappa_{2} \frac{\partial T_{2}}{\partial y}\right|_{y=0},
$$

where $\kappa_{1}$ and $\kappa_{2}$ are the thermal conductivity coefficients of the liquids in the lower and middle layers. The kinematic condition is fulfilled automatically taking into account the type of exact solutions (2). In the general case, the dynamic condition has the form

$$
\left(-p_{1} n+2 \rho_{1} \nu_{1} \mathbf{n} D\left(\mathbf{v}_{1}\right) \mathbf{n}\right)-\left(-p_{2} n+2 \rho_{2} \nu_{2} \mathbf{n} D\left(\mathbf{v}_{2}\right) \mathbf{n}\right)=2 H \sigma \mathbf{n}+\nabla_{\Gamma} \sigma .
$$

The surface tension $\sigma$ depends on the temperature $\left(\sigma=\sigma_{0}+\sigma_{T}\left(T-T_{0}\right), \sigma_{T}<0\right)$ and at the liquid-liquid interface is determined using the Antonov rule [13]: $\sigma(T)=\sigma_{2}(T)-\sigma_{1}(T)$, where $\sigma_{1}(T)$ and $\sigma_{2}(T)$ are the surface tensions of liquids filling the lower and middle layers of the system, respectively. The projection of a dynamic condition on a tangential vector is written as follows:

$$
\rho_{1} \nu_{1} u_{1 y}=\rho_{2} \nu_{2} u_{2 y}+\left(\sigma_{T 1}-\sigma_{T 2}\right) T_{x} .
$$

Here $\sigma_{T 1}$ and $\sigma_{T 2}$ are the temperature coefficients of surface tension of liquids $\left(\sigma_{1}(T)=\sigma_{01}+\right.$ $\left.+\sigma_{T 1}\left(T-T_{0}\right), \quad \sigma_{2}(T)=\sigma_{02}+\sigma_{T 2}\left(T-T_{0}\right)\right)$. The projection of a dynamic condition on a normal vector has the form

$$
p_{1}=p_{2} \text {. }
$$

Let us formulate the conditions at the interface between the liquid and the gas-vapor medium $y=h_{2}$. Continuity conditions of tangential velocities and temperatures have the form

$$
\begin{gathered}
u_{2}\left(h_{2}\right)=u_{3}\left(h_{2}\right), \\
\left.T_{2}\right|_{y=h_{2}}=\left.T_{3}\right|_{y=h_{2}} .
\end{gathered}
$$

The heat transfer condition at the $y=h_{2}$ boundary in the case when the effect of diffusion thermal conductivity is taken into account takes the following form $[5,6,8]$ :

$$
\kappa_{2} \frac{\partial T_{2}}{\partial y}-\kappa_{3} \frac{\partial T_{3}}{\partial y}-\left.\delta \kappa_{3} \frac{\partial C}{\partial y}\right|_{y=h_{2}}=-\lambda M .
$$

Here $\kappa_{3}$ is the thermal conductivity of the gas, $\lambda$ is the amount of heat released during evaporation, $M$ is the mass of liquid evaporating from a unit surface area per unit time. Also, for the 
vapor concentration at the thermocapillary boundary, the mass balance equation with the effect of thermal diffusion should be fulfilled. It has the following form $[5,10]$ :

$$
M=-D \rho_{3}\left(\left.\frac{\partial C}{\partial y}\right|_{y=h_{2}}+\left.\alpha \frac{\partial T_{3}}{\partial y}\right|_{y=h_{2}}\right) \text {. }
$$

The vapor concentration in the upper layer of the system is found using the ClapeyronClausius equation, which determines the dependence of the saturated vapor pressure $P$ on the temperature at the interface:

$$
P=P_{0} \exp \left[\frac{\lambda \mu}{R}\left(\frac{1}{T_{0}}-\frac{1}{T}\right)\right]
$$

and the Mendeleev-Clapeyron equation for an ideal gas $\rho_{v} R T=\mu P$. Here $R$ is the gas constant, $\mu$ is the molar weight of the evaporating liquid, $P_{0}$ and $T_{0}$ initial pressure and absolute temperature [14]. Assuming the equality $\rho_{v}=C \rho_{3}$ fulfilled we can write the equation for the concentration of saturated steam at the thermocapillary boundary in the following form:

$$
C(0)=C_{*} \exp \left[\left.\frac{\lambda \mu}{R T_{0}^{2}} T_{3}\right|_{y=h_{2}}\right] .
$$

Here $C_{*}$ is the vapor saturation concentration at $T_{3}=0, T_{0}$ is set equal to $20^{\circ} C\left(T_{0}=293^{\circ} \mathrm{K}\right)$. The linearized equation can be used for not too large values of $T_{3}$ :

$$
\left.C\right|_{y=h_{2}}=C_{*}\left[1+\left.\varepsilon T_{3}\right|_{y=h_{2}}\right], \quad \varepsilon=\frac{\lambda \mu}{R T_{0}^{2}}
$$

This linearization is possible due to the smallness of the parameter $\varepsilon T_{*}[10,15]$.

The kinematic condition is also performed automatically here. The projections of a dynamic condition on a tangent vector and a normal are written as follows:

$$
\begin{gathered}
\rho_{2} \nu_{2} u_{2 y}=\rho_{3} \nu_{3} u_{3 y}+\sigma_{T} T_{x}, \\
p_{2}=p_{3} .
\end{gathered}
$$

The value of $Q$ determines the gas flow rate in the upper layer according to the following formula:

$$
\int_{h_{2}}^{h_{3}} \rho_{3} u_{3} d y=Q
$$

\section{Determination of unknown constants of integration and parameters of the problem}

The presented boundary conditions (10)-(27) allow us to determine all unknown parameters of the problem $a_{j}^{i}, b_{j}, M$ and constants arising in the course of constructing exact solutions $(3)-(9) c_{k}^{i}(k=1, \ldots, 7)$.

The condition of temperature continuity at the liquid-liquid interface (15) implies the following equality of parameters: $a_{1}^{1}=a_{1}^{2}=A$, where $A$ determines the longitudinal temperature gradient at the $y=0$ boundary. Condition (11) defines $a_{1}^{2}$ through the temperature gradients and the thickness of the lower layer as follows: $a_{2}^{1}=\left(A-A_{1}\right) / h_{1}$. The parameter $a_{2}^{2}$ can be found from heat transfer condition (16): $a_{2}^{2}=a_{2}^{1} \kappa_{1} / \kappa_{2}$. Equation (12) that sets the temperature regime on the upper wall of the channel determines the relationship between the parameters $a_{1}^{3}$ 
and $a_{2}^{3}: a_{1}^{3}=A_{3}-a_{2}^{3} h_{3}$. Then due to the temperature continuity condition at the boundary $y=h_{2}(21)$ the parameter $a_{2}^{3}$ has the following form:

$$
a_{2}^{3}=\left[A+\frac{\kappa_{1}}{\kappa_{2}} \frac{h_{2}}{h_{1}}\left(A-A_{1}\right)-A_{3}\right] \frac{1}{h_{2}-h_{3}} .
$$

Note that in this statement of the problem the denominator of the fraction $1 /\left(h_{2}-h_{3}\right)$ does not become equal to zero, because if $h_{2}=h_{3}$ the thickness of the gas-vapor layer is 0 . The parameter $b_{2}$ can be found using both heat transfer condition at the liquid-gas interface (22) and mass balance equation (23). This makes it possible to determine the dependence of one of the longitudinal temperature gradients at the boundaries of the system through others. For example,

$$
A_{3}=A+\left(A-A_{1}\right) \frac{\kappa_{1}}{\kappa_{2}} \frac{h_{2}}{h_{1}}-\frac{\kappa_{1}}{\kappa_{2}}\left(A-A_{1}\right) \frac{h_{2}-h_{3}}{h_{1}} \frac{1}{1-\alpha \delta} .
$$

The relationship between the longitudinal gradients $A$ and $A_{1}$ is obtained due to the previous reasoning, the relation specifying the saturated vapor concentration and condition for the vapor absorption at the upper wall of the channel (13):

$$
A=A_{1}\left(C_{*} \varepsilon \frac{\kappa_{1}}{\kappa_{2}} \frac{h_{2}}{h_{1}}+\alpha \frac{\kappa_{1}}{\kappa_{3}} \frac{h_{2}-h_{3}}{h_{1}} \frac{1}{1-\alpha \delta}\right) /\left(C_{*} \varepsilon+C_{*} \varepsilon \frac{\kappa_{1}}{\kappa_{2}} \frac{h_{2}}{h_{1}}+\alpha \frac{\kappa_{1}}{\kappa_{3}} \frac{h_{2}-h_{3}}{h_{1}} \frac{1}{1-\alpha \delta}\right) .
$$

Taking into account dynamic conditions (18), (19) and the velocity continuity condition (14) at the liquid-liquid interface we obtain the following relations:

$$
c_{1}^{1}=\frac{\rho_{2} \nu_{2}}{\rho_{1} \nu_{1}} c_{1}^{2}, \quad c_{2}^{1}=\frac{\rho_{2} \nu_{2}}{\rho_{1} \nu_{1}} c_{2}^{2}+\frac{\sigma_{T}^{*} A}{\rho_{1} \nu_{1}}, \quad c_{3}^{1}=c_{3}^{2}
$$

(here $\left.\sigma_{T}^{*}=\sigma_{T 1}-\sigma_{T 2}\right)$. The integration constants $c_{m}^{i}(m=1,3, i=2,3)$ are determined using a system of linear algebraic equations resulting from the above reasoning and conditions (10), $(20),(25),(26),(27)$ on the system boundaries:

$$
\begin{gathered}
\frac{h_{1}^{2}}{2} \frac{\rho_{2} \nu_{2}}{\rho_{1} \nu_{1}} c_{1}^{2}-h_{1} \frac{\rho_{2} \nu_{2}}{\rho_{1} \nu_{1}} c_{2}^{2}+c_{3}^{2}=h_{1} \frac{\sigma_{T}^{*} A}{\rho_{1} \nu_{1}}-\frac{g \beta_{1}}{\nu_{1}}\left(\frac{h_{1}^{4}}{24} a_{2}^{1}+\frac{h_{1}^{3}}{6} A\right), \\
\frac{h_{3}^{2}}{2} c_{1}^{3}+h_{3} c_{2}^{3}+c_{3}^{3}=-\frac{g}{\nu_{3}}\left[\frac{h_{3}^{4}}{24}\left(\beta_{3} a_{2}^{3}+\gamma b_{2}\right)+\frac{h_{3}^{3}}{6}\left(\beta_{3} a_{1}^{3}+\gamma b_{1}\right)\right], \\
\frac{h_{2}^{2}}{2} c_{1}^{2}+h_{2} c_{2}^{2}+c_{3}^{2}-\frac{h_{2}^{2}}{2} c_{1}^{3}-h_{2} c_{2}^{3}-c_{3}^{3}=\frac{g}{\nu_{3}}\left[\frac{h_{2}^{4}}{24}\left(\beta_{3} a_{2}^{3}+\gamma b_{2}\right)+\frac{h_{2}^{3}}{6}\left(\beta_{3} a_{1}^{3}+\gamma b_{1}\right)\right]-\frac{g \beta_{2}}{\nu_{2}}\left(\frac{h_{2}^{4}}{24} a_{2}^{2}+\frac{h_{2}^{3}}{6} A\right), \\
=\rho_{3} \nu_{3} \frac{g}{\nu_{3}}\left[\frac { h _ { 2 } ^ { 3 } } { 6 } \left(\beta_{3} a_{2}^{3}+\gamma c_{1}^{2}+\rho_{2} \nu_{2} c_{2}^{2}-\rho_{3} \nu_{3} h_{2} c_{1}^{3}-\rho_{3} \nu_{3} c_{2}^{3}=\right.\right. \\
\left.\rho_{2} \nu_{2} c_{1}^{2}-\rho_{3} \nu_{3} c_{1}^{3}=\rho_{3} \nu_{3} \frac{g}{\nu_{3}}\left[\frac{h_{2}^{2}}{2}\left(\beta_{3} a_{2}^{3}+\gamma b_{1}\right)\right]-\rho_{2} \nu_{2} \frac{g \beta_{2}}{\nu_{2}}\left(\frac{h_{2}^{3}}{6} a_{2}^{2}+\frac{h_{2}^{2}}{2} A\right)+h_{2}\left(\beta_{3} a_{1}^{3}+\gamma b_{1}\right)\right]-\rho_{2}^{2} \nu_{2} \frac{g \beta_{2}}{\nu_{2}}\left(\frac{h_{2}^{2}}{2} a_{2}^{2}+h_{2}\right), \\
\left(\frac{h_{3}^{3}}{6}-\frac{h_{2}^{3}}{6}\right) c_{1}^{3}+\left(\frac{h_{3}^{2}}{2}-\frac{h_{2}^{2}}{2}\right) c_{2}^{3}+\left(h_{3}-h_{2}\right) c_{3}^{3}= \\
=\frac{Q}{\rho_{3}}-\frac{g}{\nu_{3}}\left[\frac{h_{3}^{5}}{120}\left(\beta_{3} a_{2}^{3}+\gamma b_{2}\right)+\frac{h_{3}^{4}}{24}\left(\beta_{3} a_{1}^{3}+\gamma b_{1}\right)\right]+\frac{g}{\nu_{3}}\left[\frac{h_{2}^{5}}{120}\left(\beta_{3} a_{2}^{3}+\gamma b_{2}\right)+\frac{h_{2}^{4}}{24}\left(\beta_{3} a_{1}^{3}+\gamma b_{1}\right)\right] .
\end{gathered}
$$


The temperature continuity condition (15) and the heat transfer condition at the boundary $y=0$ entail the equalities $c_{5}^{1}=c_{5}^{2}$ and $c_{4}^{1}=c_{4}^{2} \kappa_{2} / \kappa_{1}$, respectively. The system of linear algebraic equations which is a consequence of the conditions (11), (12), (13), (21), (22), (23), (24) is constructed to find the constants of integration $c_{4}^{2}, c_{5}^{2}, c_{4}^{3}, c_{5}^{3}, c_{6}, c_{7}$, as well as the value of $M$ which determines the mass of the evaporating liquid.

\section{Influence of thermal load at the system boundaries and gas flow in the upper layer on the flow structure}

Let us consider a three-layer system "liquid-liquid-gas" in the case when silicone oil and water are used as liquids filling the lower and middle layers, respectively, and air is chosen as the gas. The main parameters of the media are shown in Tab. 1 [16]. The following physical and chemical values are also used: $D=0.22 \cdot 10^{-4} \mathrm{~m}^{2} / \mathrm{s}, \sigma_{T 1}=-0.697 \cdot 10^{-5} \mathrm{~N} /(\mathrm{m} \mathrm{K}), \sigma_{T 2}=-1.514 \cdot 10^{-5}$ $\mathrm{N} /(\mathrm{m} \mathrm{K}), \lambda=2.547 \cdot 10^{6} \mathrm{~W} \mathrm{~s} / \mathrm{kg}, C_{*}=0.05, \varepsilon=0.0651 / \mathrm{K}$; the parameters $\alpha$ and $\delta$ are taken equal $-0.5 \cdot 10^{-2}$ and $10^{-3}$, respectively.

Table 1. Physicochemical parameters of the problem

\begin{tabular}{|l|c|c|c|c|}
\hline Parameter & & Silicone oil & Water & Air \\
\hline$\rho$ & $\mathrm{kg} / \mathrm{m}^{3}$ & $0.935 \cdot 10^{3}$ & $0.997 \cdot 10^{3}$ & 1.35 \\
\hline$\nu$ & $\mathrm{m}^{2} / \mathrm{s}$ & $10^{-5}$ & $0.893 \cdot 10^{-5}$ & $1.35 \cdot 10^{-5}$ \\
\hline$\beta$ & $1 / K$ & $1.08 \cdot 10^{-3}$ & $2.07 \cdot 10^{-4}$ & $3.66 \cdot 10^{-3}$ \\
\hline$\kappa$ & $\mathrm{W} /(\mathrm{m} \mathrm{K})$ & 0.134 & 0.6167 & 0.026 \\
\hline$\chi$ & $\mathrm{m}^{2} / \mathrm{s}$ & $0.96 \cdot 10^{-7}$ & $1.47 \cdot 10^{-7}$ & $0.214 \cdot 10^{-4}$ \\
\hline
\end{tabular}

Fig. 2 shows the velocity profiles for various values of the gas flow rate $Q$ in the upper layer of the system. The thickness of the silicone oil layer is $3 \cdot 10^{-3} \mathrm{~m}$, water $-4 \cdot 10^{-3} \mathrm{~m}$, air $-5 \cdot 10^{-3} \mathrm{~m}$. The longitudinal temperature gradients at the system boundaries have constant values: $A_{1}=1$ $\mathrm{K} / \mathrm{m}, A=1.85 \mathrm{~K} / \mathrm{m}, A_{3}=0.635 \mathrm{~K} / \mathrm{m}$. As the values of $Q$ increase, the maximum velocity in the gas-vapor layer increases significantly. The liquid profiles change slightly in this case.

Qualitative and quantitative changes in flows in liquids are observed in the case when the values of longitudinal temperature gradients change, and the gas flow rate remains constant at the same values of the layer thicknesses (see Fig. 3). The longitudinal velocity at the interfaces takes positive values for sufficiently large values of gradient $A_{1}\left(A_{1}=2 \mathrm{~K} / \mathrm{m}, A_{1}=1 \mathrm{~K} / \mathrm{m}\right.$, a solid line and a short dashed line, respectively). A purely Poiseuille's flows characterized by positive values of velocities in all layers of the system are observed. In the case when the longitudinal gradient $A_{1}$ takes the value $-1 \mathrm{~K} / \mathrm{m}$, reverse flows appear at the interfaces (large dashed line, Fig. 3). Thus, as the longitudinal temperature gradients increase, the flow type changes from thermocapillary, due to the predominance of Marangoni forces, to Poiseuille flow (see $[4,5]$ ).

Fig. 4 shows a system where the thickness of the silicone oil layer is $5 \cdot 10^{-3} \mathrm{~m}$, water $4 \cdot 10^{-3} \mathrm{~m}$, air $-3 \cdot 10^{-3} \mathrm{~m}$. The gas flow rate $Q$ is set to $10^{-6} \mathrm{~kg} /(\mathrm{m} \mathrm{s})$, as in the case shown in the Fig. 3. The maximum longitudinal velocity increases significantly with a decrease in the thickness of the gas-vapor layer in it. There are no qualitative changes in the velocity profiles of liquids in comparison with the previous case.

In the case of a further decrease in the thickness of the gas-vapor layer, the maximum value 


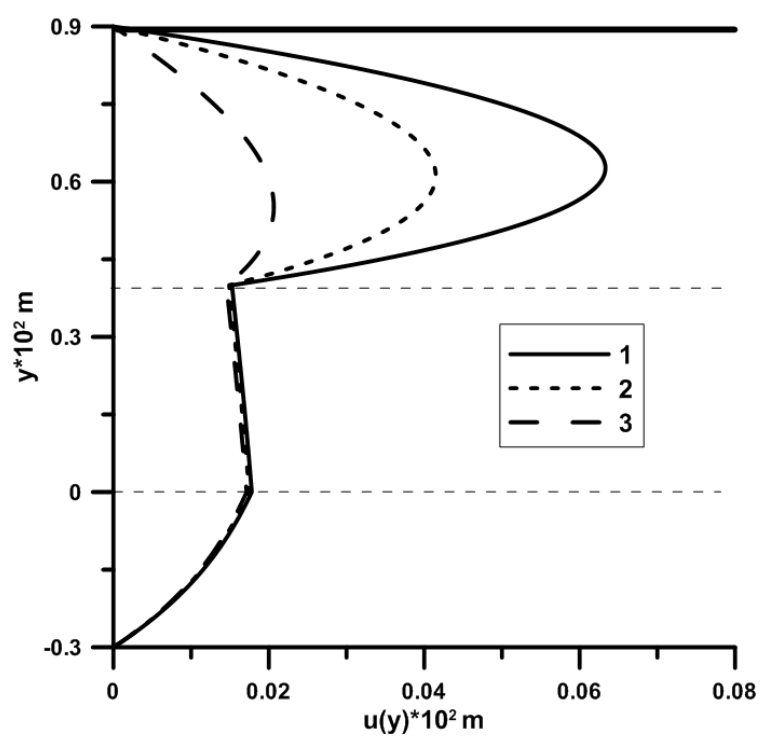

Fig. 2. Influence of gas flow rate $Q$ on the velocity profile. Here $A_{1}=1 \mathrm{~K} / \mathrm{m}, h_{1}=3 \cdot 10^{-3} \mathrm{~m}$, $h_{2}=4 \cdot 10^{-3} \mathrm{~m}, h_{3}=9 \cdot 10^{-3} \mathrm{~m} .1-Q=3 \cdot 10^{-6} \mathrm{~kg} /(\mathrm{m} \mathrm{s}) ; 2-Q=2 \cdot 10^{-6} \mathrm{~kg} /(\mathrm{m} \mathrm{s}) ;$ $3-Q=10^{-6} \mathrm{~kg} /(\mathrm{m} \mathrm{s})$

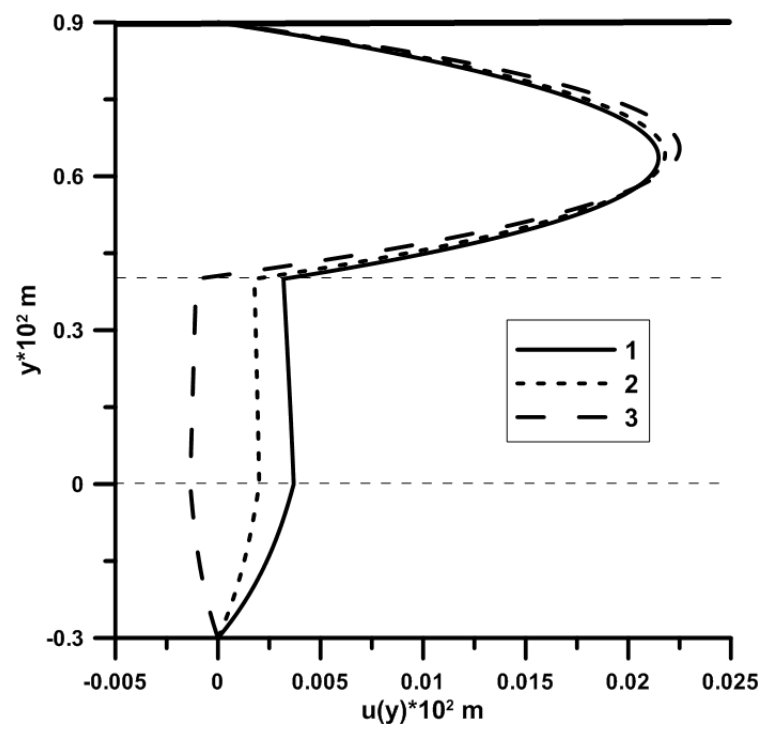

Fig. 3. Influence of the longitudinal temperature gradient $A_{1}$ on the velocity profile. Here $Q=10^{-6} \mathrm{~kg} /(\mathrm{m} \mathrm{s}), h_{1}=3 \cdot 10^{-3} \mathrm{~s}, h_{2}=4 \cdot 10^{-3} \mathrm{~s}, h_{3}=9 \cdot 10^{-3} \mathrm{~m} . \quad 1-A_{1}=2 \mathrm{~K} / \mathrm{m}$; $2-A_{1}=1 \mathrm{~K} / \mathrm{m} ; 3-A_{1}=-1 \mathrm{~K} / \mathrm{m}$

of the longitudinal velocity in the upper layer of the system continues to increase (see Fig. 5). The gas flow rate $Q$ and the longitudinal temperature gradient on the lower wall of the channel $A_{1}$ are chosen the same as in the previous case. Note also that, in this case, reverse flows are not observed at thermocapillary interfaces. 


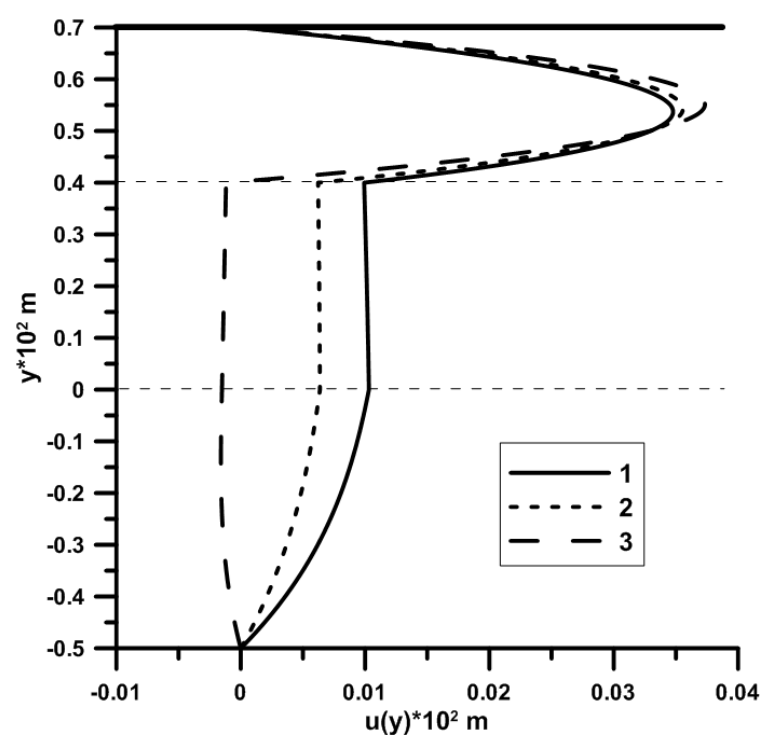

Fig. 4. Influence of the longitudinal temperature gradient $A_{1}$ on the velocity profile. Here $Q=10^{-6} \mathrm{~kg} /(\mathrm{m} \mathrm{s}), h_{1}=5 \cdot 10^{-3} \mathrm{~m}, h_{2}=4 \cdot 10^{-3} \mathrm{~m}, h_{3}=7 \cdot 10^{-3} \mathrm{~m} . \quad 1-A_{1}=2 \mathrm{~K} / \mathrm{m}$; $2-A_{1}=1 \mathrm{~K} / \mathrm{m} ; 3-A_{1}=-1 \mathrm{~K} / \mathrm{m}$

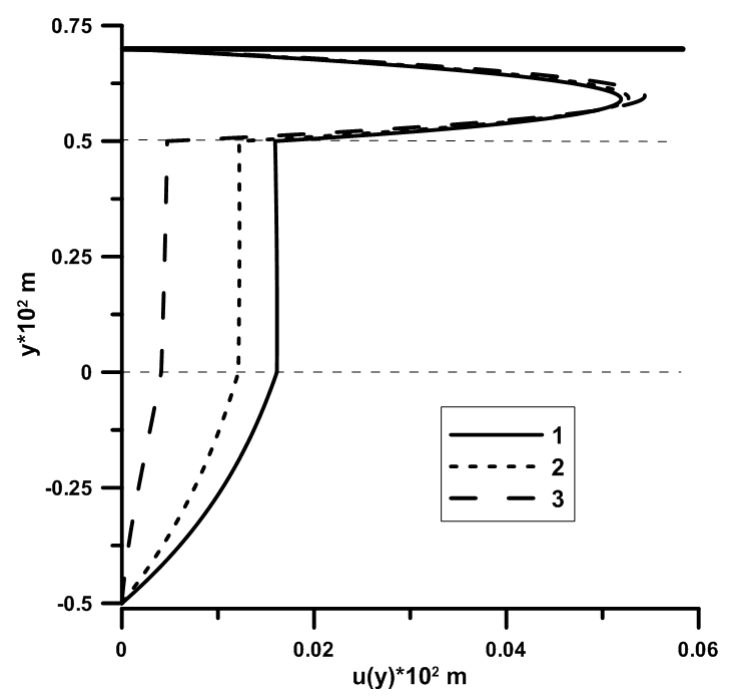

Fig. 5. Influence of the longitudinal temperature gradient $A_{1}$ on the velocity profile. Here $Q=10^{-6} \mathrm{~kg} /(\mathrm{m} \mathrm{s}), h_{1}=5 \cdot 10^{-3} \mathrm{~m}, h_{2}=5 \cdot 10^{-3} \mathrm{~m}, h_{3}=7 \cdot 10^{-3} \mathrm{~m} .1-A_{1}=2 \mathrm{~K} / \mathrm{m}$; $2-A_{1}=1 \mathrm{~K} / \mathrm{m} ; 3-A_{1}=-1 \mathrm{~K} / \mathrm{m}$

\section{Conclusion}

An exact solution of the system of Navier-Stokes equations in the Boussinesq approximation describing the flow in a three-layer system "liquid-liquid-gas" under conditions of a given gas flow rate is constructed. Evaporation is taken into account at the liquid-gas interface, the in- 
terfaces are thermocapillary surfaces. Using the "silicone oil-water-air" system as an example, the influence of the temperature regime on the solid walls of the channel, gas flow rate and layer thicknesses on the change in velocity profiles is considered.

Within the framework of the proposed problem, it is planned to consider various conditions on the channel walls for temperature and vapor concentration. It is interesting to study the influence of various system parameters on the distribution of temperature and vapor concentration in the system, as well as on the intensity of evaporation from the liquid-gas interface. The construction of such exact solutions is of particular relevance in connection with the possibility of investigating the degree of influence of various physical factors on the nature of flows and the intensity of evaporation, as well as making predictions about the results of experiments.

The work was carried out in accordance with the State Assignment of the Russian Ministry of Science and Higher Education entitled "Modern methods of hydrodynamics for environmental management, industrial systems and polar mechanics" (Govt. contract code: FZMW-2020-0008, 24 January 2020).

\section{References}

[1] V.B.Bekezhanova, O.N.Goncharova, Problems of evaporative convection (Review), Fluid Dynamics, 53(2018), 69-102. DOI: 10.1134/S001546281804016X.

[2] Y.V.Lyulin et.al., Measurement of evaporation rate from surface to surface liquid layer under the gas flow, Pis'ma $v$ ZhETF, 41(2015), no. 14, 1-7 (in Russian).

[3] B.Scheid, Onset of thermal ripples at the interface of an evaporating liquid under a flow of inert gas, Exp. Fluids, 52(2012), 1107-1119.

[4] V.B.Bekezhanova, O.N.Goncharova, E.V.Rezanova, I.A.Shrfer, Stability of two-layer fluid flows with evaporation at the interface, Fluid Dynamics, 52(2017), 189-200.

DOI: $10.1134 /$ S001546281702003X.

[5] V.B.Bekezhanova, O.N.Goncharova, I.A.Shefer, Analysis of an exact solution of problem of the evaporative convection (Review). Part I. Plane case, Journal of Siberian Federal University. Mathematics and Physics, 11(2)(2018), 178-190.

DOI: $10.17516 / 1997-1397-2018-11-2-178-190$.

[6] V.K.Andreev, Y.A.Gaponenko, O.N.Goncharova, V.V.Pukhnachev, Mathematical models of convection, De Gruyter, 2012.

[7] G.Z.Gershuni, E.M.Zhukhovitsky, Convective stability of an incompressible fluid, Moscow, Nauka, 1972 (in Russian).

[8] O.N.Goncharova, E.V.Rezanova, Example of an exact solution of the stationary problem of two-layer flows with evaporation at the interface, J. of Appl. Mech. and Tech. Phys., $\mathbf{5 5}(2014)$, no. 2, 247-257.

[9] V.K.Andreev, N.L.Sobachkina, The movement of a binary mixture in flat and cylindrical areas, Krasnoyarsk, Siberian federal university, 2012 (in Russian).

[10] M.I.Shliomis, V.I.Yakushin, Convection in a two-layer binary system with evaporation, Uch. Zap. Perm. Gos. Univ., Ser. Gidrodyn. 4(1972), 129-140 (in Russian). 
[11] G.A.Ostroumov, Free convection under the conditions of the internal problem. MoscowLeningrad, Gos. izd-vo tehniko-teoreticheskoy lieraturi, 1952 (in Russian).

[12] R.V.Birikh, About thermocapillary convection in a horizontal liquid layer, PMTF 3(1966), 69-72 (in Russian).

[13] G.N.Antonov, Sur la tension superficielle à la limite de deux couches, J. Chim. Phys., 5(1907), 372-385.

[14] I.Prigozhin, Chemical thermodynamics, Novosibirsk, Nauka, 1966 (in Russian).

[15] T.A.Ghezzehei, R.C.Trautz, S.Finsterle, et al., Modeling coupled evaporation and seepage in ventilated cavities, Vadose Zone J., 3(2004), 806-818.

[16] V.B.Bekezhanova, O.N.Goncharova, N.A.Ivanova, D.S.Klyuev, Instability of a two-layer system with deformable interface under laser beam heating $J$. of Siberian Federal University. Math. and Phys., 12(2019), no. 5, 543-550. DOI: 10.17516/1997-1397-2019-12-5-543-550.

\title{
Построение точных решений, описывающих трехслойные течения с испарением в горизонтальном канале
}

Екатерина В. Резанова Алтайский государственный университет Барнаул, Российская Федерация

\begin{abstract}
Аннотация. В работе рассматривается течение в трехслойной системе "жидкость-жидкость-газ" в горизонтальном канале с твердыми непроницаемыми стенками. Процесс испарения на термокапиллярной границе раздела жидкости и газа принимается во внимание. При моделировании течения в верхнем слое, заполненном газо-паровой смесью, учитываются эффекты Соре и Дюфура. В качестве математической модели рассматривается система уравнений Навье-Стокса в приближении Буссинеска. На стенках канала задан тепловой режим. Испарение жидкости моделируется с помощью условий на границе раздела "жидкость-газ". Построено точное решение специального вида, описывающее течение в трехслойной системе. Представлены профили скорости на примере системы "силиконовое масло-вода-воздух" при различных значениях расхода газа, продольных градиентов температуры на границах системы, толщин жидких и газопарового слоев.
\end{abstract}

Ключевые слова: трехслойная система, точные решения, испарение, эффект Соре, эффект Дюфура. 